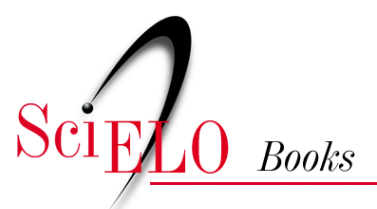

\title{
Posfácio \\ Ciência, saúde e política no regime milita: “O massacre de manguinhos"
}

\author{
Wanda Hamilton
}

HAMILTON, W., Ciência, saúde e política no regime milita: "O massacre de manguinhos". In: LENT, H. O massacre de Manguinhos [online]. 2nd ed. Rio de Janeiro: Editora FIOCRUZ: Edições Livres, 2019, pp. 77-97, Memória viva collection. ISBN: 978-85-7541-640-2. https://doi.org/10.7476/9788575416402.0004.

All the contents of this work, except where otherwise noted, is licensed under a Creative Commons Attribution 4.0 International license.

Todo o conteúdo deste trabalho, exceto quando houver ressalva, é publicado sob a licença Creative Commons Atribição $\underline{4.0}$. 


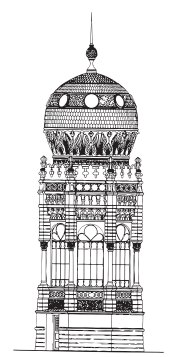




\section{Posfácio}

\section{Ciência, saúde e política no regime militar: "O Massacre de Manguinhos"}

— m agosto de 1986, a Fundação Oswaldo Cruz (Fiocruz) reintegrou em seus quadros os dez cientistas cassados e aposentados compulsoriamente pela ditadura militar (1964-1985). Este fato se revestiu de um duplo sentido: por um lado, reparar a injustiça cometida pelo regime militar, e, por outro, afirmar ao mesmo tempo o processo de redemocratização da instituição, que se iniciava na gestão de Antônio Sérgio da Silva Arouca (1985-1989).

Em pouco mais de 30 anos, a Fiocruz se transformou progressivamente em uma instituição estratégica do Estado, atuante nos campos da ciência, da tecnologia, da inovação, da educação e da produção tecnológica de serviços e insumos para a promoção da saúde da população e a efetivação da cidadania, alicerçada em uma estrutura organizacional transparente, democrática e participativa. As eleições internas para presidente e diretor de unidade e a criação de fóruns institucionais coletivos, como os conselhos deliberativos e o Congresso Interno, são exemplos de mecanismos decisórios que buscam construir consenso em bases democráticas em torno do projeto institucional. 
Foi justamente a falta de consenso a respeito do papel social da instituição, em um contexto político centralizador e autoritário, um dos principais fatores que levaram à cassação dos cientistas do Instituto Oswaldo Cruz (IOC), no episódio que ficou conhecido como "O Massacre de Manguinhos", termo cunhado por Herman Lent (1978).

Durante as três primeiras décadas de sua existência (1900-1930), o Instituto Oswaldo Cruz construiu seu papel na ciência biomédica brasileira em função de um modelo de organização de suas práticas de pesquisa e de legitimação de suas atividades na vida pública nacional que se caracterizava pela estreita relação entre a investigação científica e os interesses presentes na sociedade, sobretudo pela capacidade de identificar e responder aos problemas concretos da saúde pública brasileira (STEPAN, 1976; BENCHIMOL, 1990; SCHWARTZMAN, 2001).

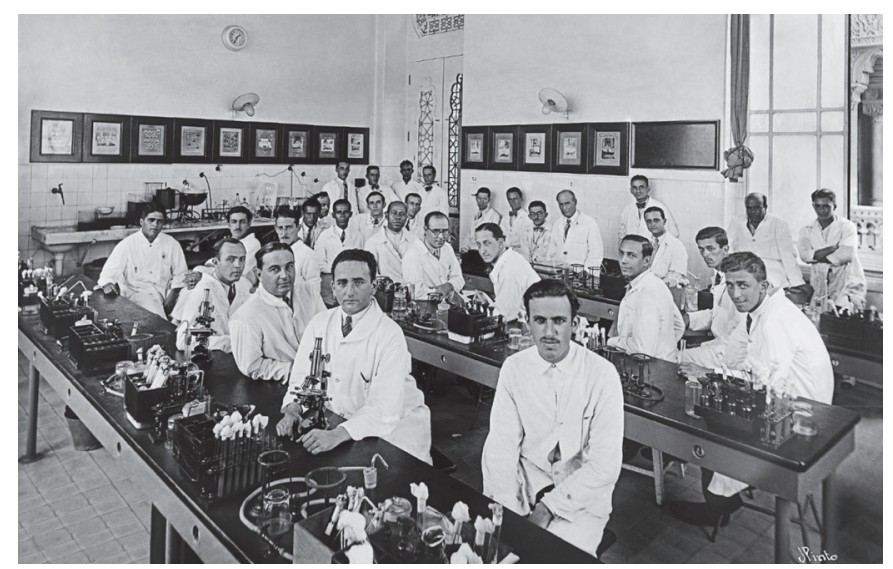

Laboratório de pesquisa do IOC, Curso de Aplicação, 1931. Foto: J. Pinto. Acervo Casa de Oswaldo Cruz. 
Essas condições começariam a se alterar a partir do governo de Getúlio Vargas. O IOC, até então vinculado à pasta da Justiça, passou, em 1930, para a jurisdição do então criado Ministério da Educação e Saúde Pública, perdendo progressivamente a centralidade que possuíra até então no âmbito da formulação e implementação de políticas e medidas sanitárias para o país. ${ }^{1}$ Este fato, aliado à degradação dos salários, à evasão de pesquisadores, à deterioração das instalações físicas e equipamentos, colocava sérios obstáculos para a reprodução do projeto institucional (AZEVEDO et al., 2002).

Uma nova mudança institucional ocorreria em 1953, quando o Instituto Oswaldo Cruz passou a vincular-se diretamente ao Ministério da Saúde, naquele momento recém-separado do Ministério da Educação. Essa reforma organizacional não implicou mudanças significativas, pois as estruturas institucionais se mantiveram as mesmas, tendo ocorrido basicamente uma separação entre os serviços que diziam respeito à área da educação e os da saúde (HAMILTON; FONSECA, 2003). Contudo, a criação do Departamento Nacional de Endemias Rurais em 1956, cujas prioridades consistiam em organizar, coordenar e executar os serviços de combate às doenças endêmicas consideradas prioritárias, indica a progressiva centralização das atividades do Ministério da Saúde (BUSS et al., 1976).

Nesse contexto, o IOC perdeu definitivamente, além de sua autonomia política, a influência sobre a política sanitária global, restringindo-se à produção 


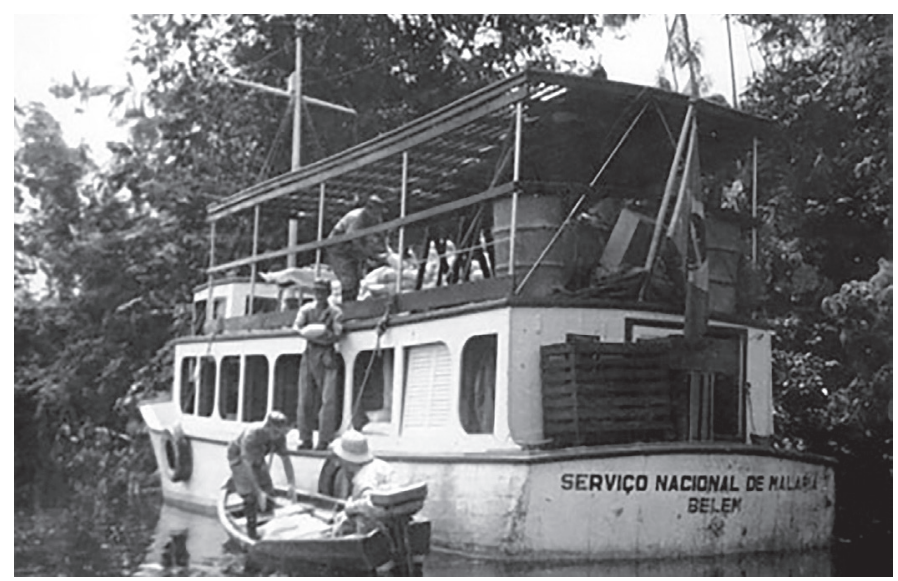

Distribuição de sal cloroquinado pelo Serviço Nacional de Malária, na Amazônia, em 1952, década em que foi criado o Departamento Nacional de Endemias Rurais (DNERu). Acervo Casa de Oswaldo Cruz.

de soros, vacinas e reagentes. A instituição tornouse um órgão fundamental ao andamento das campanhas organizadas pelo governo, dedicando seu orçamento à produção de imunobiológicos para atender às demandas crescentes do Ministério. Desde 1950, Manguinhos é o único produtor da vacina contra a febre amarela no Brasil e foi um dos principais produtores da vacina antivariólica. Esta última se intensificou a partir do lançamento da Campanha da Erradicação da Varíola no Brasil, em conjunto com a Organização Mundial da Saúde (OMS), no início da década de 1960. Contando com o apoio financeiro da Organização Pan-Americana de Saúde (Opas) e introduzindo a técnica da vacina liofilizada, o IOC, que produzia 9,522 milhões de doses em 1962, passou a produzir 42 milhões de 
doses em 1966 para serem distribuídas em todo o território nacional.

A Segunda Guerra Mundial influiu de maneira decisiva sobre o processo de institucionalização da ciência moderna, gerando um forte impacto na relação entre ciência, tecnologia e sociedade. A ciência passou a ser reconhecida como um bem nacional, um instrumento valioso para fins militares, econômicos e sociais. Afirmava-se então que a pesquisa básica, entendida como uma atividade sem fins práticos, constituía o alicerce do desenvolvimento de tecnologias e inovações. Essa perspectiva, que seria chamada de modelo linear de inovação, contribuiu para o aumento do prestígio público dos cientistas e os lançou em um intenso ativismo político em prol do desenvolvimento da ciência (AZEVEDO et al., 2002).

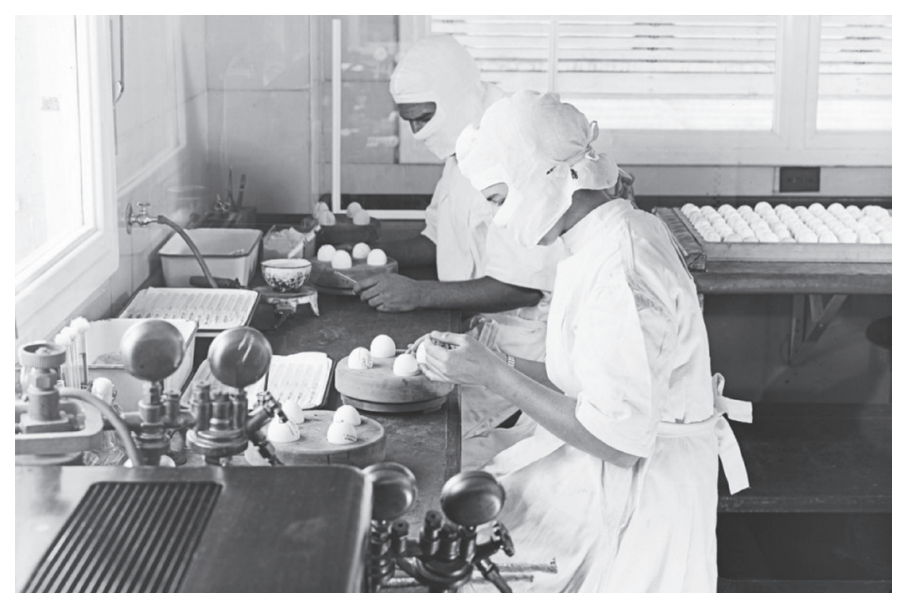

Laboratório do IOC, produção da vacina de febre amarela na primeira metade do século XX. Acervo Casa de Oswaldo Cruz. 
Na esteira dessas transformações foi fundada, em 1948, a Sociedade Brasileira para o Progresso da Ciência (SBPC), com vistas a organizar os interesses da comunidade científica nacional, a qual passou a pleitear a participação dos cientistas, junto ao governo, e a organização da atividade científica em moldes profissionais, o que requeria uma série de condições a serem asseguradas por ele, entre elas, garantir: autonomia e financiamento para a pesquisa; estabelecimento do tempo integral; melhoria salarial; e a criação de uma carreira de pesquisa nas universidades e nos institutos públicos.

Paralelamente à mudança nas relações entre o IOC e o campo da saúde pública, ocorreu uma transformação na dinâmica de institucionalização da atividade científica, que resultou em um crescente processo de profissionalização da ciência no país, cujo marco fundamental é a criação do Conselho Nacional de Pesquisa (CNPq), em 1951. O Estado firmava-se como patrocinador direto da pesquisa, por meio de bolsas e auxílios financeiros, orientado pela necessidade de equiparar $o$ Brasil às nações desenvolvidas, garantindo a participação da comunidade científica na definição e implementação da política científica (MOREL, 1979).

Vários laboratórios do Instituto Oswaldo Cruz passaram a receber seu auxílio, principalmente as divisões de Fisiologia, Entomologia e Anatomia Patológica. Em face da falta de recursos, a 
pesquisa científica se manteve graças ao aporte de financiamentos externos como os do próprio $\mathrm{CNPq}$ e da Fundação Ford, que sustentavam, por exemplo, o produtivo laboratório de Hematologia conduzido por Walter Oswaldo Cruz.

A crença de que a aplicação social do conhecimento científico seria uma consequência de investimentos em pesquisa básica, a longo prazo, teve o impacto de reorientar a agenda de pesquisa do IOC a partir dos anos de 1950. Nas gestões de Francisco da Silva Laranja Filho (1954-1955), Amilcar Vianna Martins (1958-1960), Tito Arcoverde Cavalcanti (1960-1961) e Joaquim Travassos da Rosa (1962-1964) dispõese de um órgão colegiado de gestão da instituição, o Conselho Deliberativo, composto pelos chefes de divisões e de uma orientação que passaria a dar relevância ao desenvolvimento dos campos básicos do conhecimento biomédico e biológico, e não somente às investigações aplicadas ao campo da saúde pública.

Nesse aspecto, cabe ressaltar a crescente proeminência alcançada pelos grupos atuantes nos campos da fisiologia e da zoologia, liderados respectivamente por Miguel Ozório de Almeida e Lauro Travassos, cujos trabalhos voltavamse fundamentalmente para aspectos básicos do conhecimento biomédico e biológico. Era justamente nesses dois campos do conhecimento que atuava, desde os anos de 1930 e 1940, a maioria dos cientistas que estaria na lista das cassações em $1970 .^{2}$ 
Outro aspecto relevante do movimento pelo desenvolvimento da ciência foi a mobilização em torno da criação do Ministério da Ciência, originada na SBPC no final da década de 1950. Os pontos fundamentais da proposta eram garantir à comunidade científica um espaço de participação nas decisões a respeito de um projeto científico definido nacionalmente e implementar uma política visando à autonomia e à liberdade científica para fazer face aos critérios utilitários adotados por órgãos governamentais. Só assim seria resgatado o papel que a ciência cumprira no processo de desenvolvimento brasileiro.

Vários pesquisadores do IOC estavam articulados a esse movimento, principalmente Herman Lent,
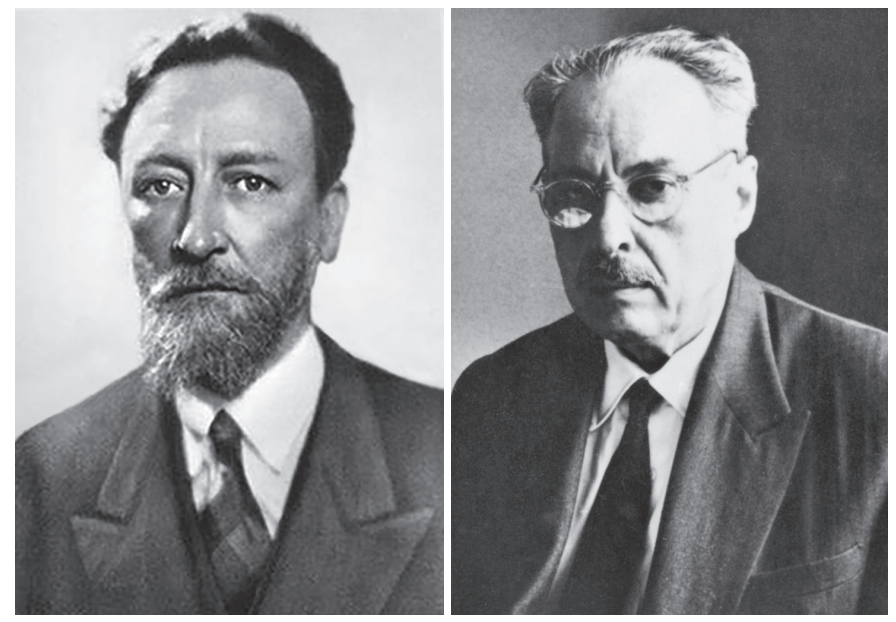

Pesquisadores Miguel Ozório de Almeida e Lauro Travassos, s.d. Acervo Casa de Oswaldo Cruz. 
Haity Moussatché, Walter Oswaldo Cruz e Tito Cavalcanti. Segundo esse grupo, a transferência do Instituto Oswaldo Cruz para a esfera do novo ministério o transformaria em uma instituição de investigação básica, libertando a comunidade científica do peso de ter de trabalhar em assuntos exclusivamente de interesse médico e da responsabilidade pela produção de soros e vacinas, que pesavam na balança na hora da distribuição de recursos (LENT, 1978).

Apesar da consonância desse discurso com o clima desenvolvimentista do governo de Juscelino Kubitschek (1956-1961), essas reivindicações não chegariam a se efetivar. Sua expressão mais concreta seria a organização da Universidade de Brasília, planejada por esse grupo. Alguns dos cientistas mobilizados na implementação dessa instituição estariam, anos depois, na lista dos cassados e aposentados pelo regime militar.

No outro lado dessa dicotomia, encontramos a orientação de que o IOC deveria manter-se essencialmente como um instituto de pesquisa aplicada. Esta corrente veiculava a ideia de que, diante dos escassos recursos de que dispunha a instituição, deveriam ser priorizadas a produção de imunobiológicos e a pesquisa voltada para doenças que atingiam a população. Nessa perspectiva, uma instituição associada às políticas de saúde pública como o Instituto Oswaldo Cruz deveria reforçar os setores que correspondiam às demandas do Ministério da Saúde. A pesquisa sem preocupação 
com a aplicabilidade do conhecimento ocuparia, portanto, um segundo plano.

Foram essas transformações que colocaram em questão o perfil institucional do IOC, gerando um estado de polarização e tensão interna decorrentes da falta de consenso a respeito do seu perfil (BRITTO et al., 1988). Os cientistas do IOC, e suas bases de apoio social, participaram dessa polêmica ativamente, cada qual representando uma identidade profissional específica que tentava impor as suas concepções e interesses científicos políticos.

No dia $1^{\circ}$ de abril de 1964, em meio à grave crise política, o presidente João Goulart (1961-1964) foi deposto pelo golpe militar, que instituiu um regime que alteraria o modelo político e econômico vigente e firmaria as bases para a articulação de uma nova aliança no interior do Estado, na qual as Forças Armadas se constituíram como fração hegemônica. A ascensão do marechal Castelo Branco à Presidência da República caracterizouse por dois fenômenos complementares. Por um lado, procurou-se a retomada do desenvolvimento econômico, reservando ao capital estrangeiro um papel preponderante. Por outro, sob o lema da "segurança nacional", a ordem institucional foi quebrada sob o argumento da necessidade de combater o comunismo (MOTTA, 2000).

Inaugurando uma série de medidas arbitrárias, o presidente decretou o Ato Institucional no 1 (AI-1), que cassou os direitos de centenas de militares e 
políticos de oposição. Foram instaurados inquéritos policiais militares (IPMs) que atingiram a maioria das instituições da esfera pública.

Esse contexto político inaugurou no Instituto Oswaldo Cruz uma fase crítica da sua história, marcada pela polarização dos conflitos e pela intervenção direta dos mecanismos repressivos que caracterizaram a ditadura militar.

Entre 1964 e 1970, diferentes órgãos de segurança e informação acompanharam as atividades dos cientistas do Instituto Oswaldo Cruz. O primeiro inquérito militar na instituição iniciou-se sob a direção do general Aluizio Falcão para apurar atos de subversão e corrupção entre seus funcionários. Paralelamente, um inquérito civil para tratar de assuntos administrativos foi instaurado pelo Ministério da Saúde. Uma terceira investigação foi instaurada em 1966. Sob acusação direta de Rocha Lagoa, então diretor de Manguinhos, foram intimados, pelo serviço de segurança do Ministério da Saúde, os cientistas que contavam com maiores financiamentos para suas pesquisas, obtidos de instituições privadas e governamentais.

Após a conclusão dos inquéritos, que nada provaram contra os cientistas na esfera civil e militar, o regime manteve o controle das atividades consideradas subversivas ocorridas no IOC, como mostram documentos secretos produzidos pelos diferentes órgãos de informação. ${ }^{3}$ 
O ministro da Saúde Raimundo de Britto (19651967), político oriundo da UDN e ex-secretário do governo Carlos Lacerda, deixou clara sua intenção de adaptar as instituições às novas condições impostas pelo regime militar, afirmando: "As ideias exóticas que em Manguinhos foram infiltradas serão banidas definitivamente [...]. Manguinhos de amanhã será uma colmeia de trabalho e não um foco de ideias subversivas". ${ }^{4}$

No dia 23 de junho, Raimundo de Britto nomeou o médico Francisco de Paula da Rocha Lagoa para chefiar o Instituto Oswaldo Cruz. Suas credenciais para ocupar o cargo, além de um fervoroso anticomunismo, consistiam na realização do curso da Escola Superior de Guerra (ESG) em 1963 no apoio do Arcebispo do Rio de Janeiro, D. Jaime Câmara, e no vínculo familiar com políticos da UDN.

No seu discurso de posse, Rocha Lagoa, funcionário de Manguinhos desde a década de 1940, estabeleceria suas ligações com o poder político militar, assumindo o papel de representante de seus ideais dentro da instituição: "Será sob a égide da família, da ciência, da cruz e dos ideais de desenvolvimento, bem-estar e segurança do Brasil que pretendemos encetar esta jornada e moldar nossas ações em prol da maior grandeza de nossa pátria" ${ }^{5}$

Procurando adequar-se às diretrizes gerais do Ministério da Saúde, o novo diretor criticava 
a desorganização dos trabalhos das gestões anteriores e estabelecia um programa de atividades que valorizava o estudo de problemas de patologia nacional e o incremento da produção de soros e vacinas. Todos os funcionários em cargos de chefia foram substituídos por aqueles que se adequassem melhor à nova orientação e o Conselho Deliberativo foi desativado. Assim, o grupo de pesquisadores que se mobilizava em prol de uma maior participação na definição de uma política científica nacional, e que até então vinha ocupando importantes cargos dentro da instituição perdeu espaço dentro do IOC.

A direção do IOC ainda enviou ofícios a entidades internacionais e universidades pedindo que os auxílios financeiros passassem

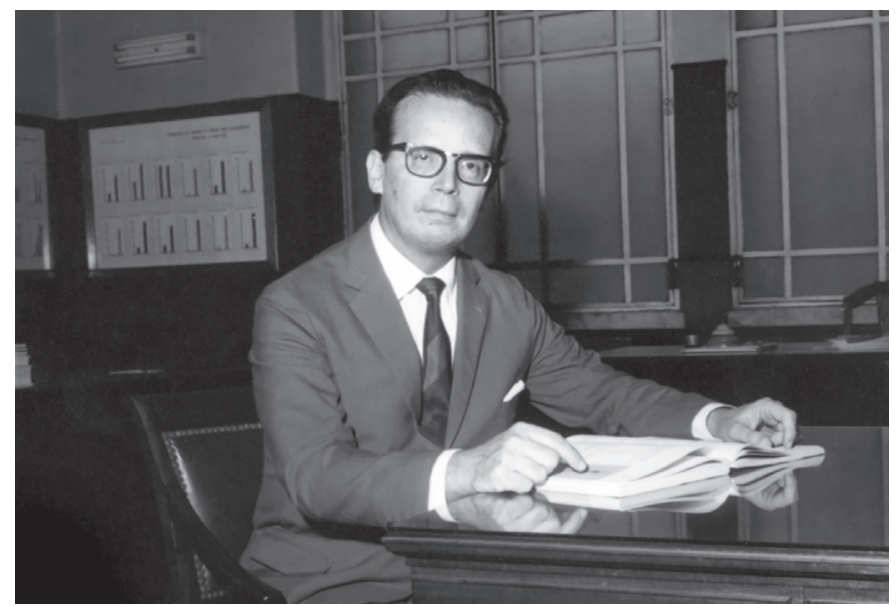

Dr. Francisco de Paula da Rocha Lagoa no interior do Castelo Mourisco, s.d.

Acervo Casa de Oswaldo Cruz. 
pelo seu crivo ao invés de seguirem diretamente para os pesquisadores beneficiados. Com isto, a direção poderia alocar recursos para os setores de seu interesse, principalmente para as divisões de microbiologia e virologia, que tiveram um aumento considerável no número de doses de vacinas e soros produzidos. Algumas instituições, porém, não aceitaram a pressão do IOC. A Fundação Ford, por exemplo, que destinaria, em 1964, 40 mil dólares para financiar principalmente a seção de hematologia, suspendeu seu auxílio.

Além de dificultar a captação de recursos externos, a centralização administrativa permitia que a direção destinasse as verbas para as áreas consideradas prioritárias, relegando outros setores a um segundo plano. Rocha Lagoa tinha, como diretor do IOC, assento garantido no Conselho Nacional de Pesquisa. Lá, ele também exerceu pressão para que os auxílios concedidos a Herman Lent e Haity Moussatché não se renovassem, sob a alegação de que desejava estabelecer trabalhos em outras linhas; consequentemente, o $\mathrm{CNPq}$ acabou por não renovar as bolsas.

Por meio da imprensa e de contatos com altos funcionários do governo, o grupo de oposição continuava a combater a transformação do Instituto Oswaldo Cruz no que eles consideravam ser apenas uma fábrica de vacinas, reiterando a necessidade de criação de um Ministério da Ciência. Haity Moussatché concedeu, na época, uma entrevista que lhe valeu uma interpelação 
da direção e, posteriormente, uma pena de repreensão constante no ofício $n^{\circ} 26$, de 1965, do IOC. ${ }^{6}$ O Jornal do Brasil de 6 de janeiro informava: "Haity Moussatché denuncia a Raimundo de Britto: 'A política dominante no Instituto tende a transformá-lo numa autêntica farmácia com sérios prejuízos ao setor de pesquisa científica'".

No início de 1965, os cientistas conseguiram uma audiência com o ministro da Saúde Raimundo de Britto para denunciar a transformação do IOC em um órgão de solução de problemas sanitários imediatos em detrimento das pesquisas. Eles propuseram a criação de um instituto de saúde pública que se encarregasse da produção de insumos e dos estudos nosológicos. O ministro manteve seu apoio à direção de Manguinhos, afirmando: "Vêm sendo feitas, nestes últimos dias, insistentes acusações à atual direção do Instituto Oswaldo Cruz, o que está a exigir esclarecimento deste Gabinete, tal a inconsistência das afirmações veiculadas". ${ }^{7}$

No plano externo, o grupo intensificava sua mobilização a favor da criação do Ministério da Ciência, projeto mais afinado com suas necessidades, conforme Herman Lent: "A definição que nós víamos como mais palpável era a passagem para o Ministério da Ciência [...] Era uma posição pública assumida claramente, considerando que era a única maneira de defender a instituição que vinha caindo cada vez mais" (LENT, 1982). 
Em junho de 1965, cientistas representando várias instituições de pesquisa, entre eles Walter Oswaldo Cruz, Haity Moussatché, Tito Cavalcanti e Herman Lent pelo IOC, participam de uma audiência com o Ministro do Planejamento, Roberto Campos, para expor a ideia do Ministério da Ciência. Tito Cavalcanti relembra o encontro: "Arthur Moses, que era presidente da $A B C$ [Academia Brasileira de Ciências], resolveu convocar um grupo de pesquisadores para apresentar a Roberto Campos, que era Ministro do Planejamento, nossa ideia de Ministério da Ciência [...] Fiz a apresentação e a entreguei por escrito a Roberto Campos. No fim ele só fez a afirmação de que os institutos devem ser órgãos de execução; órgãos de pesquisa devem ser só as universidades (Cavalcanti, 1985)".

De antemão, o ministro condenava a ideia do Ministério da Ciência, indicando o que futuramente procuraria se aplicar com a Reforma Universitária de 1968, na qual o ensino e a pesquisa apareceriam dissociados dos institutos públicos e ligados às universidades.

De fato, a proposta de criação do Ministério da Ciência ${ }^{8}$ não angariou apoio político, e, após 1964, os cientistas que a defendiam foram acusados de serem subversivos e de conspirarem contra o Estado (SANTOS, 2016). A tentativa de vinculação a uma nova secretaria foi encarada pela direção do Instituto como atitude de insubordinação ao Ministério da Saúde, passível de severas punições, como demonstra um documento elaborado por Rocha Lagoa, no qual sugere a remoção dos "notórios 
comunistas de alta periculosidade" sob o pretexto de "resguardar o bom nome da instituição, pois a campanha difamatória em curso pela imprensa e pelo rádio fere diretrizes governamentais básicas" 9 .

O governo optaria por desenvolver uma política de tecnologia de grande porte, tendo como base de sustentação as Forças Armadas e as grandes empresas multinacionais, através de acordos de importação de know-how e equipamentos. A autonomia de operações e o controle de recursos estratégicos definiram a energia nuclear como área prioritária de investimentos, seguida dos setores de comunicações, produção de armamentos e computadores, todos concentrados pelo Estado (SCHWARTZMAN, 1981).

No Programa Estratégico de Desenvolvimento (1968-1970), acentuou-se o importante papel da educação para o progresso tecnológico. A Reforma Universitária de 1968 se caracterizaria por medidas técnicasvisandotornarosistemadeensinosuperiormais eficiente. Simultaneamente, foram implementadas medidas de caráter punitivo, restringindo os aspectos políticos e críticos da universidade. $\mathrm{O}$ governo incentivava o desenvolvimento científico e tecnológico, mas afastava dos centros de decisão os elementos mais qualificados da comunidade científica, desarticulando os setores mais críticos e contrariando os ideais de autonomia, liberdade e participação.

Após 1968, várias universidades e institutos, entre eles a Universidade de São Paulo (USP), a 
Universidade do Estado do Rio de Janeiro (Uerj), a Universidade Federal de Minas Gerais (UFMG),

o Centro Brasileiro de Pesquisas Físicas (CBPF), a Universidade de Brasília (UnB), teriam professores e pesquisadores cassados ou aposentados por atos institucionais, reflexo do clima político da época, marcado pelo endurecimento do regime militar, que impôs o Ato Institucional n ${ }^{\circ} 5$ (AI-5). Este conferia plenos poderes ao Executivo, prevendo a suspensão dos direitos políticos de qualquer cidadão, a censura prévia à imprensa e o redimensionamento do Serviço Nacional de Informações (SNI), medidas necessárias à atuação das Forças Armadas envolvidas com a repressão.

A ascensão do general Médici à Presidência da República em outubro de 1969, inaugurando os anos de maior repressão e controle do regime militar, e a nomeação de Rocha Lagoa para o Ministério da Saúde configurariam o quadro para os acontecimentos do dia $1^{\circ}$ de abril de 1970 . No dia seguinte, o Diário Oficial publicava o decreto, baseado no AI-5, que suspendia os direitos políticos por dez anos de Haity Moussatché, Herman Lent, Moacyr Vaz de Andrade, Augusto Cid Mello Perissé, Hugo de Souza Lopes, Sebastião José de Oliveira, Fernando Braga Ubatuba e Tito Cavalcanti. Como a punição não implicava o afastamento de Manguinhos, um novo decreto aposentava e elevava para dez a lista de cientistas atingidos, incluindo os nomes de Domingos Arthur Machado Filho e Masao Goto. 
O panorama político repressivo era avesso a fórmulas integradoras. O conflito de posições no IOC encerrouse quando o grupo de oposição à diretoria foi excluído dos seus quadros. As medidas repressivas foram o recurso utilizado para alijar os cientistas cujas vozes eram dissonantes às orientações do regime militar, sob a acusação difusa de comunismo. Os cientistas portadores de um discurso alternativo de política institucional foram sumariamente afastados do Instituto Oswaldo Cruz em um período que se caracterizou pelo fechamento dos canais de participação, pela centralização do poder nas Forças Armadas e pela eliminação dos setores críticos da sociedade civil (HAMILTON, 1989).

O saldo desse processo significou, na verdade, a derrota das aspirações de ambos os grupos, atingindo tanto a produção científica quanto imunobiológica, além de ter provocado uma séria crise de paralisia institucional que teve reflexos em todos os setores do Instituto Oswaldo Cruz. Incorporado à Fundação Instituto Oswaldo Cruz, criada em 1970 e denominada Fundação Oswaldo Cruz em 1974, o IOC se defrontou até meados da década de 1980 com linhas de pesquisas interrompidas, formação de jovens pesquisadores paralisadas, laboratórios fechados, falta de pessoal, acordos de cooperação suspensos e importantes coleções científicas sob sério risco de destruição.

Wanda Hamilton

Pesquisadora da Casa de Oswaldo Cruz/Fiocruz 


\section{Notas}

1 A formulação e implementação de políticas sanitárias passaria, progressivamente, a ser exercida por profissionais com formação e especialização em saúde pública. A esse respeito, ver Fonseca (2007).

2 Na divisão de Zoologia estavam lotados Herman Lent, Hugo de Souza Lopes, Domingos Arthur Machado e Sebastião José de Oliveira; na divisão de Fisiologia Haity Moussatché, Tito Arcoverde Cavalcanti e Fernando Braga Ubatuba. Masao Goto e Moacyr Vaz de Andrade desempenhavam suas atividades no laboratório de Micologia, chefiado até 1964 por Antônio Arêa-Leão; e Augusto Cid de Mello Perissé pertencia ao laboratório de química.

3 Para uma análise mais detalhada dos processos gerados pelos órgãos de segurança, ver Santos (2016).

4 Correio da Manhã, 24/04/1965.

5 Tribuna Médica, 26/06/1964.

6 Casa de Oswaldo Cruz. Fundo Instituto Oswaldo Cruz, Seção Direção, Dossiê 005 (Ordens de Serviço), Livro 00263, Portaria n². (BR RJ COC 02-05-005).

7 Correio da Manhã, 30/01/1965

8 O Ministério da Ciência e da Tecnologia foi criado durante o governo de José Sarney (1985-1990) pelo Decreto no 91.146 de 15 de março de 1985.

9 Arquivo Nacional. Serviço Nacional de Informação - SNI (Agência Rio de Janeiro). Informe Especial, de $1^{\circ}$ de dezembro de 1967, do diretor do Instituto Oswaldo Cruz ao ministro da Saúde. (ARJ-ACE-5216-69). 


\section{Referências bibliográficas}

AZEVEDO, Nara; FERREIRA， Luiz Otávio; KROPF, Simone Petraglia; HAMILTON, Wanda. A profissionalização da atividade científica no IOC (1935-1960). Mimeo. Rio de Janeiro: COC/Fiocruz, 2002.

BENCHIMOL, Jaime Larry. Manguinhos do sonho à vida. A ciência na Belle Époque, Rio de Janeiro: Fundação Oswaldo Cruz/Casa de Oswaldo Cruz, 1990.

BRITTO, Nara; BENCHIMOL, Jaime Larry; HAMILTON, Wanda. Do Instituto Soroterápico Federal à Fundação Oswaldo Cruz. Fundação Oswaldo Cruz. Ciência e Saúde: a Fiocruz do Futuro. I Congresso Interno. Fase III. Suplen. p. 31-35, 1988.

BUSS, Paulo Marchiori; SHIRAIWA, Tizuko; MARANHÃO, Eduardo. Ministério de Saúde e saúde coletiva. A história de 20 anos (1953/1974). Mimeo. Rio de Janeiro: IMS/Uerj, 1976.

CAVALCANTI, Tito. Tito Cavalcanti. (depoimento, 1985). Rio de Janeiro, COC/ Fiocruz, 1985.

FONSECA, Cristina Maria Oliveira. Saúde no Governo Vargas (1930-1945: dualidade institucional de um bem público. Rio de Janeiro: Fiocruz, 2007.

HAMILTON, Wanda; FONSECA, Cristina Maria Oliveira. Política, atores e interesses no processo de mudança institucional: a criação do Ministério da Saúde em 1953. História, Ciências, Saúde - Manguinhos, vol. 10(3): 791-825, set-dez. 2003.

HAMILTON, Wanda. 'Massacre de Manguinhos': Crônica de uma morte anunciada, Cadernos da Casa de Oswaldo Cruz, No 1, V. 1, Rio de Janeiro: Casa de Oswaldo Cruz, Fiocruz, 1989.

LENT, Herman. Herman Lent. (depoimento, 1982). Rio de Janeiro: CPDOC/FVG, 1982.

LENT, Herman. O massacre de Manguinhos. Rio de Janeiro: Avenir, 1978.

MOREL, Regina Lúcia de Moraes. A política científica no Brasil, São Paulo: Queiroz, 1979.

MOTTA, Rodrigo Patto Sá. Em guarda contra o perigo vermelho: o anticomunismo no Brasil (19171964). Tese (Doutorado em História Econômica). Faculdade de Filosofia, Letras e Ciências Humanas (USP), São Paulo, 2000.

SANTOS, Daniel Guimarães Elian dos. Ciência, política e segurança nacional: o "massacre de Manguinhos" (1964-1970). Dissertação (mestrado em História das Ciências e da Saúde) da Casa de Oswaldo Cruz, Fiocruz, 2016.

SCHWARTZMAN, Simon. Um espaço para a ciência: a formação da comunidade científica no Brasil. Brasília, Ministério da Ciência e Tecnologia, Centro de Estudos Estratégicos, 2001.

SCHWARTZMAN, Simon. Ciência, universidade e ideologia. A política do conhecimento. Rio de Janeiro, Zahar, 1981.

STEPAN, Nancy. Beginnings of Brazilian Science: Oswaldo Cruz, medical research and policy, 1890-1920, New York: Science History Publications, 1976. 